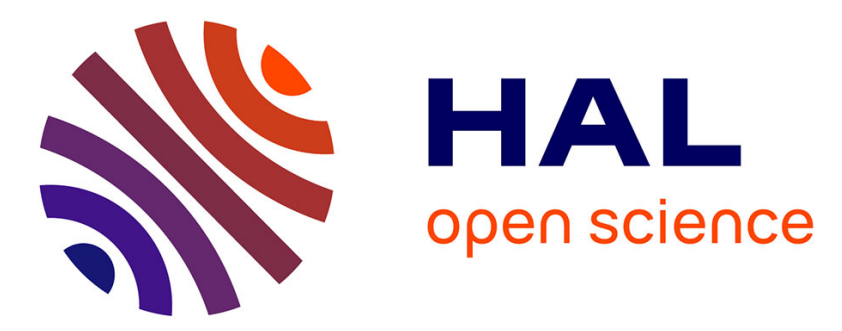

\title{
Olive baboons, Papio anubis, adjust their visual and auditory intentional gestures to the visual attention of others
}

Marie Bourjade, Adrien Meguerditchian, Audrey Maille, Florence Gaunet, Jacques Vauclair

\section{To cite this version:}

Marie Bourjade, Adrien Meguerditchian, Audrey Maille, Florence Gaunet, Jacques Vauclair. Olive baboons, Papio anubis, adjust their visual and auditory intentional gestures to the visual attention of others. Animal Behaviour, 2014, 87, pp.121-128. 10.1016/j.anbehav.2013.10.019 . hal-00932293

\section{HAL Id: hal-00932293 https://hal.science/hal-00932293}

Submitted on 11 Apr 2014

HAL is a multi-disciplinary open access archive for the deposit and dissemination of scientific research documents, whether they are published or not. The documents may come from teaching and research institutions in France or abroad, or from public or private research centers.
L'archive ouverte pluridisciplinaire HAL, est destinée au dépôt et à la diffusion de documents scientifiques de niveau recherche, publiés ou non, émanant des établissements d'enseignement et de recherche français ou étrangers, des laboratoires publics ou privés. 
1 Olive baboons, Papio anubis, adjust their visual and auditory intentional gestures to the visual

2 attention of others

3 Marie Bourjade $^{\mathrm{a}, \mathrm{b}, *}$, Adrien Meguerditchian ${ }^{\mathrm{b}, \mathrm{c}}$, Audrey Maille $^{\mathrm{d}}$, Florence Gaunet ${ }^{\mathrm{c}}$, Jacques

4 Vauclair $^{\mathrm{a}}$

$5 \quad{ }^{a}$ Research Centre in the Psychology of Cognition, Language and Emotion, PsyCLE, Aix-

6 Marseille University, Aix-en-Provence, France

$7 \quad{ }^{\mathrm{b}}$ Centre National de la Recherche Scientifique, Station de Primatologie UPS 846, Rousset,

8 France

$9 \quad{ }^{\mathrm{c}}$ Laboratoire de Psychologie Cognitive, Aix-Marseille University, Marseille, France

10 d UMR 6552 Ethos 'Ethologie Animale et Humaine', Université de Rennes 1-CNRS, Station

11 Biologique, Paimpont, France

12 Received 15 April 2013

13 Initial acceptance 21 June 2013

14 Final acceptance 25 September 2013

MS. number: 13-00319R

*Correspondence and present address: M. Bourjade, Laboratoire de Psychologie Cognitive,

17 Aix-Marseille University, 3 place Victor Hugo, 13331 Marseille Cedex 3, France.

18 E-mail addresses: marie.bourjade@ univ-amu.fr, marie.bourjade@ gmail.com (M. Bourjade).

Although nonhuman primates' gestural communication is often considered to be a likely precursor of human language, the intentional properties in this communicative system have not yet been entirely elucidated. In particular, little is known about the intentional nature of 
monkeys' gestural signalling and related social understanding. We investigated whether olive baboons can (1) adjust their requesting gestures to the visual attention of the experimenter with special emphasis on the state of the eyes (open versus closed), and (2) flexibly tailor visual and auditory-based gestures to elaborate their communication as a function of whether or not the experimenter can see them. Using a food-requesting paradigm, we found monkeys able to favour either visual or auditory-based requesting gestures to match the experimenter's visual attention. Crucially, when the human was not visually attending, they silenced visual gestures to some extent but performed more attention-getting gestures. This is, to our knowledge, the first report of monkeys elaborating attention-getting signals to compensate for communication breakdown. Gestural communication was also supported by gaze alternation between the experimenter's face and the food, especially when the human was visually attending. These findings offer evidence that olive baboons understand the state of the eyes in others' visual attention and use requesting gestures intentionally. They emphasize that Old World monkeys shift to acoustic communication when the recipient is not visually attending. In contrast to that of human infants and great apes, this acoustic communication is purely gestural, not vocal.

\section{Keywords}

audience attention, gestural communication, intentionality, language, nonhuman primate

Intentional communication is collaborative in essence since it requires mutual attention from both parties in the interaction (Tomasello, Carpenter, Call, Behne, \& Moll, 2005). When producing gestural requests such as pointing gestures, the sender should be able to perceive the visual attention of the recipient (Butterworth, 2004). In human infants, taking a partner's 
attentional state into account when gesturing is seen only from around 15 months of age (Bates, Camaioni, \& Volterra, 1975; Franco \& Butterworth, 1996; Leavens \& Hopkins, 1999). The best evidence of an understanding of attention in children is the coordination with others' attention to external targets, also called 'joint attention' (Butterworth, 2004; Scaife \& Bruner, 1975). This ability is considered critical for the development of both language and the ability to attribute mental states to others (Camaioni, Perucchini, Bellagamba, \& Colonnesi, 2004; Reddy, 2004).

Nonhuman primates do communicate with gestures too. A communicative gesture has recently been defined as 'any non-vocal bodily action directed to a recipient that is mechanically ineffective and represents a meaning, beyond itself, that is in part manifested by others of the social group' (Scott \& Pika, 2012, p. 158; but see Perlman, Tanner, \& King, 2012 for an alternative view of mechanical effectiveness). Great apes and cercopithecines produce these communicative signals, and so far research has mostly emphasized their use, function and language-like properties (Pika \& Liebal, 2012). Indeed, this gestural system of communication is often considered to be the most likely precursor of human language (Corballis, 2003; Pollick \& de Waal, 2007; Vauclair, 2004) owing to shared similarities such as the flexible and voluntary use of gestures (Liebal \& Call, 2012 Meguerditchian, Cochet, \& Vauclair, 2011), or the brain specialization for gesturing (Corballis, 2003; Hopkins \& Vauclair, 2012). However, whether nonhuman primates gesture with the genuine intent to modify their recipient's behaviour, attention or knowledge has not yet been entirely elucidated (Gómez, 2007). Although there is solid evidence that great apes are sensitive to their partner's attentional state when gesturing, little is known about the intentio nal nature of monkeys' gestural signalling and related social understanding (Call \& Tomasello, 2007; Scott \& Pika, 2012). Specifically, for both great apes and monkeys it is not clear whether the relevant cues to attention of the recipient are the eyes or more general indicators such as head 
and body orientation (Emery, 2000; Povinelli \& Eddy, 1996; Povinelli, Eddy, Hobson, \& Tomasello, 1996; but see Kaminski, Call, \& Tomasello, 2004).

Deictic gestures that refer to external targets are used by nonhuman primates to perform requests (Gómez, 2005; Pika, 2008). To be considered as intentional, they must fulfil several criteria used for prelinguistic children's pointing (Bates et al., 1975; Leavens, 2004): (1) the gesture is goal-oriented and the signal persists or is completed with other signals until the desired outcome is reached; (2) the gesture is adjusted in accordance to the attentional state of the audience, whose attention can be regained by the use of additional attentiongetting behaviours; and (3) the gesture is supported by visual orienting behaviours alternating between the recipient and the distal object of interest (gaze alternation). Evidence is accumulating that great apes use visual gestures only if the recipient is visually attending (e.g. bonobos, Pan paniscus: Pika, Liebal, Call, \& Tomasello, 2005; orang-utans, Pongo pygmaeus: Liebal, Pika, \& Tomasello, 2006; gorillas, Gorilla gorilla: Genty, Breuer, Hobaiter, \& Byrne, 2009; chimpanzees, Pan troglodytes: Hobaiter \& Byrne, 2011) and persist with (e.g. Genty \& Byrne, 2010; Liebal, Call, \& Tomasello, 2004) or elaborate (Cartmill \& Byrne, 2007; Leavens, Russell, \& Hopkins, 2005) their gestures until they achieve a certain goal. However, attempts to determine which cues to attention are used by apes and monkeys to adjust their communication have led to mixed results. While it is often not possible to characterize the state of the eyes of individuals in naturalistic settings (e.g. Emery, 2000; Genty et al., 2009), experimental studies have further demonstrated that nonhuman primates generally use body orientation (e.g. great apes: Hostetter, Cantero, \& Hopkins, 2001; Kaminski et al., 2004; Povinelli et al., 1996; monkeys: Hattori, Kuroshima, \& Fujita, 2010; Meunier, Prieur, \& Vauclair, 2012) or face orientation (e.g. great apes: Tempelmann, Kaminski, \& Liebal, 2011; monkeys: Maille, Engelhart, Bourjade, \& Blois-Heulin, 2012) as an indicator of a human's attention, although they may sometimes use face orientation only 
when the human's body is oriented towards them (e.g. chimpanzees: Kaminski et al., 2004).

However, there is little evidence that nonhuman primates adjust their signals to the open and directed state of the recipient's eyes (but see Hattori et al., 2010; Hostetter, Russell, Freeman, \& Hopkins, 2007). Instead, many studies have failed to demons trate that subjects tailor their gestural signals as a function of the state of the experimenter's eyes (Kaminski et al., 2004; Povinelli et al., 1996; Theall \& Povinelli, 1999). Although chimpanzees have been reported to move into someone's visual field before starting to gesture rather than using auditory or tactile signals to regain attention (Liebal, Call, Tomasello, \& Pika, 2004), two studies showed that chimpanzees favoured the modality of communication that best fitted the experimenter's visual attention (Leavens, Hostetter, Wesley, \& Hopkins, 2004), using auditory signals specifically when the experimenter could not see them (Hostetter et al., 2007). While this may constitute the best evidence so far that great apes can finely tune their gestures to the level of attention of the recipient, there is no such evidence for monkeys, to which this stringent paradigm remains to be applied.

We addressed this question in olive baboons using a food-requesting paradigm.

Baboons use two distal threat gestures in their natural communication, i.e. 'slapping ground' and 'rubbing ground' (Estes, 1991; Kummer, 1968), usually performed towards an obviously attending partner (Meguerditchian \& Vauclair, 2006; Meguerditchian et al., 2011). They are further known to rely on the use of gaze cues by conspecifics for soliciting help in conflicts (Packer, 1977) and for deceptive communication (Whiten \& Byrne, 1988). In experimental settings baboons gestured more towards a human facing them than one oriented away (Meunier et al., 2012), but no study has disambiguated which cues to attention they relied on. We manipulated the experimenter's visual attention by varying the orientation of the experimenter's whole body, including head (front/back), and the state of her eyes (open/closed). We then addressed whether baboons (1) adjust their requesting gestures to the 
visual attention of the experimenter with special emphasis on the state of her eyes, and (2) flexibly tailor visual and auditory signals to elaborate their communication as a function of whether or not the experimenter can see them. If baboons are able to use the state of the eyes as a cue to visual attention, they should produce more requests when the experimenter's eyes are open than when they are closed. If they not only use the state of the eyes as a cue to attention, but also understand the role of open eyes as an attentional state that is specific to their visual behaviour, baboons should tailor their gestural communication to the visual attention of the experimenter, and therefore produce more auditory-based gestures than visual gestures when the experimenter cannot see them compared to when she can. However, if baboons rely on more general cues to attention such as body orientation, they should produce more requests when the experimenter is facing them than when the experime nter is oriented away.

\section{$<$ H1 $>$ Methods}

$<H 2>$ Subjects

The experiments took place in the Primate Station of the Centre National de la Recherche Scientifique (UPS 846, Rousset, France; Agreement number for conducting experiments on vertebrate animals: D13-087-7). Sixteen baboons, 10 males and six females, ranging in age from 6 to 16 years were tested between August 2011 and March 2012 (see Appendix Table A1). All subjects lived in reproductive social groups comprising one adult male, two to five adult females and their immature offspring (up to 2 years old). Groups had free access to 14 
$\mathrm{m}^{2}$ outdoor areas connected to $12 \mathrm{~m}^{2}$ indoor areas. The enclosures were enriched by wooden platforms and vertical structures of different heights, in both the outdoor and indoor areas. All monkeys were fed four times a day with industrial monkey pellets, seed mixture, fresh vegetables and fruits. Water was available ad libitum and subjects were never deprived of food or water during testing. Subjects were tested in their outdoor area, and only females were partly isolated from dominant individuals (which were kept inside) during testing. The experimental procedure complied with the current French laws and the European directive 86/609/CEE. According to Article 3 (definitions) of the current European directive, this experiment does not qualify as an experimental procedure and therefore does not require institutional ethics approval.

$<H 2>$ Apparatus

Prior to each test session, we placed inside the cage a concrete block perpendicularly to the mesh, at about $90 \mathrm{~cm}$ from the ground so that subjects could gesture at about the height of a person. The mesh was equipped with a 10x60 $\mathrm{cm}$ opening through which the baboons could freely pass their arms. During testing, a Plexiglas panel of $80 \times 35 \mathrm{~cm}$ with two $10 \times 15 \mathrm{~cm}$ holes separated by $25 \mathrm{~cm}$ from centre to centre was fixed to the mesh over the opening (see Supplementary Videos S1-S4). This panel was devised to facilitate subsequent recording of baboons' gestures on video footage. Baboons were hence allowed to beg through the holes toward s an experimenter standing $1 \mathrm{~m}$ in front of the cage. Two video cameras were placed 2 $m$ in front of the cage on both sides of the experimenter at an angle of $45^{\circ}$ to the subject's midline. All sessions were videotaped at a rate of 30 frames/s. 
All subjects were previously trained to beg through one of the holes of the Plexiglas panel to request the food reward held in the experimenter's hand (see the Appendix for the full procedure). Baboons were then tested for their requesting behaviour in four conditions. In the control condition, the condition Out, the experimenter deposited a piece of banana $(4 \mathrm{~cm}$ long throughout the study) on the ground, $1 \mathrm{~m}$ in front of the cage, and left the test area (see Supplementary Video S1). In the other three conditions, the test conditions, the experimenter stood $1 \mathrm{~m}$ in front of the cage holding a piece of banana in one hand always in sight of the subject: (1) Eyes open: the experimenter faced and looked at the subject (see Supplementary Video S2); (2) Eyes closed: the experimenter faced the subject but kept her eyes closed (see Supplementary Video S3); (3) Back turned: the experimenter was oriented away from the subject but held the food behind her back (see Supplementary Video S4). Note that the procedure so as to control for possible habituation to the procedure (see full details in 
Two different types of manual gestures were observed during the study and scored on the videos for further analysis. Begging gestures were visual gestures consisting of extending one or two arm(s) with fingers and hand(s) being in line with the arm(s) (Fig. 1). Attention-getting gestures were auditory-based gestures consisting of banging the Plexiglas panel. Visual orienting behaviour that took the form of gaze alternation bouts between the experimenter's face and the food was also recorded. A first main observer coded all occurrences of begging gestures and attention-getting behaviours at 30 frames/s using a VLC media player. A begging gesture started when the wrist crossed the mesh and ended with the partial or complete withdrawal of the arm. A new occurrence was scored whenever the subject brought its arm back, with the elbow being inside the cage, and extended it again. A new occurrence of attention-getting gesture was scored each time the subject banged the Plexiglas panel producing distinct sounds. A second main observer coded all occurrences of visual orienting behaviour frame by frame using Avidemux 2.5 (32-bit). Gaze alternation bouts were recorded based on the conservative number of four consecutive looks alternating between the experimenter's face and the piece of banana. For reliability purposes, $15 \%$ of the video material was randomly assigned to two novel observers who were naïve to the experiment. This resulted in a total of 40 experimental trials, each of $30 \mathrm{~s}$, in 10 different test sessions. One novel observer coded the begging and attention-getting gestures while the other coded gaze alternation bouts. Reliability was assessed within pairs of main and novel observers and was high for both gestures (Cohen's $k=0.82$ ) and gaze alternation bouts (Cohen's $k=0.76$ ). 
We used an approach of multimodel inference to determine which cues to attention most affected the responses of the subjects (Burnham \& Anderson, 2004). We processed the numbers of begging gestures, attention-getting gestures and gaze alternation bouts produced by the 16 subjects over all test sessions across experimental conditions. Missing data occurred for one subject (Tulie) in the last test session and were considered as such in the models. We followed a three-step procedure: (1) we fitted several models varying the nature of cues to attention as fixed effects (Table 1); (2) we selected the models that best fitted the observed data; and (3) we performed tests of significance on the retained models.

As the frequency distribution of all dependent variables was not normal, we selected a

Poisson family with a log link function adapted to count data for fitting generalized linear mixed models with 'condition' as fixed effect (i.e. Main Models). Pseudoreplication caused by repeated observations of the same individual was taken into consideration by adding the individual as a random effect. Second, we examined the possible variation of behavioural responses over time (habituation) by fitting models with the interaction between 'condition' and 'block' of test sessions as fixed effects and 'individual' and 'block' as random effects (i.e. Time Models). The first two test sessions were pooled as block 1 and the last two test sessions as block 2. Third, we tested which postural cues to attention had the strongest effect on dependent variables by performing nested models of the parameter 'condition' (i.e. Nested Models). This procedure allowed us to weight the relative influence of the different cues to attention (e.g. state of the eyes, body orientation) 'nested' in the parameter 'condition', and 
advantageously replace traditional post hoc comparisons. To test whether the effect of the state of the eyes could be stronger than the effect of head and body orientation, we pooled the Eyes closed and Back turned conditions into condition Cannot see to compare with condition Can see (i.e. Eyes open). To test whether the effect of head and body orientation could be stronger than the effect of the state of the eyes, we pooled the Eyes open and Eyes closed conditions into condition Front to compare with condition Back (i.e. Back turned).

$<$ H3 > Model selection

For each dependent variable we proceeded to select the best fitting models on the basis of the lowest AICc (i.e. Akaike information criterion corrected, Table 1), which applies a secondorder correction adapted to small samples (Burnham \& Anderson, 2004).

$<H 3>$ Test of significance

We used chi-square tests of the log-likelihood ratios to test whether the retained models fitted the observed data significantly better than a hypothetical null model in which no fixed effect had been implemented (Brown \& Prescott, 2006). All tests were two tailed and were performed with R 2.10.1 software (http://cran.r-project.org) with level of significance set at 0.050 .

\section{$<$ H1 $>$ Results}


264 The baboons adjusted their begging behaviour to the visual attentional state of the

experimenter (Fig. 2). The experimental condition most affected the number of begging gestures (Table 1, Main Model). Baboons gestured more when the experimenter had her eyes open than in the other three conditions, Eyes closed (Wald test: $z=-2.28, P=0.023$ ), Back turned (Wald test: $z=-9.30, P<0.001$ ) and Out (Wald test: $z=-11.64, P<0.001$ ). Body orientation by itself (Table 1, Front/Back Model) and the state of the experimenter's eyes alone (Table 1, Can see/Cannot see Model) were not better predictors of subjects' responses than experimental conditions mixing both cues (Table 1), suggesting that both played a role in the understanding of attentional state by baboons. In a transfer test performed by novel experimenters so as to exclude possible conditioned responses driven by the sight of the main experimenter, baboons showed very similar responses (see the Appendix and Fig. A1).

The baboons displayed significantly more gaze alternation bouts (Table 1, Main Model: Fig. 3) when the experimenter had her eyes open than when her eyes were closed (Wald test: $z=-2.13, P=0.033$ ) or when her back was turned (Wald test: $z=-6.41, P<$ 0.001). Body orientation by itself (Table 1, Front/Back model) and the state of the experimenter's eyes alone (Table 1, Can see/Cannot see model) were not better predictors of subjects' responses than experimental conditions mixing both cues (Table 1) suggesting that both played a role in the understanding of attentional state by baboons.

\section{$<$ H2 > Attraction of Recipient's Visual Attention}


Of the 16 subjects, 14 displayed attention-getting gestures, i.e. auditory-based gestures consisting of banging the apparatus. Banging was more frequent when the experimenter was present than when she was absent (Wald test: $z=-4.22, P<0.001$ ), and when the experimenter could not see the subject than when she could (Wald test: $z=0.029, P=0.029$ ), during the first two test sessions only (Table 1, Can See/Cannot See Nested Model).

Restricting our analysis to these two sessions in which no habituation to the procedure was likely to occur, we found that baboons performed more banging when the experimenter could not see them than when she could (one-sample permutation test: $t=2.09, P=0.021$; Fig. 4 ). Body orientation of the experimenter either alone (Table 1, Front/Back Model) or in combination with the state of her eyes (Table 1, Main Model) were not better predictors of the subjects' banging than being seen or not by the experimenter (Table 1).

\section{$<H 2>$ Adjustment of Gestures to Recipient's Visual Attention}

Considering the first two test sessions, we investigated whether subjects favoured visual requests (food-begging gestures) over auditory-based gestures (banging) when the experimenter could see them compared to when she could not. Gesture types produced by the baboons were affected by the possibility of being seen by the experimenter (Fisher's exact probability test: $P<0.001)$. Baboons made more visual requests when the experimenter could see them than when she could not. Conversely, they banged more when the experimenter could not see them than when she could (Fig. 5).

\section{$<$ H1 $>$ Discussion}


Three novel findings resulted from this study. First, baboons tailored communicative signals

311

312

313

314

315

316

317

from different modalities as a function of a human's visual attention based on the state of the eyes. Second, gestures were accompanied by gaze alternation between the human's face and the food. Third, monkeys spontaneously elaborated attention-getting signals when there was a communication breakdown. Until now, this latter ability was considered as a feature unique to communication of humans and great apes. Collectively, these findings provide solid evidence that baboons understand the state of the eyes in others' visual attention and use requesting gestures intentionally.

The primate brain contains neurons that are selectively responsive to eye direction, head orientation and body orientation, possibly as part of a hierarchical process for determining the direction of another's attention (see Emery, 2000 for a review). In baboons, the eye region is the primary focus of attention during processing of both humans' and conspecifics' faces (Martin-Malivel, Mangini, Fagot, \& Biederman, 2006) and is essential for face recognition (Kyes \& Candland, 1987). Monkeys also distinguish directed from averted gazes from both a conspecific and a human (Keating \& Keating, 1982) and they follow the gaze direction of other individuals (Tomasello, Call, \& Hare, 1998), sometimes relying on eye gaze direction only (e.g. in rhesus macaques, Macaca mulatta: Lorincz, Baker, \& Perrett, 2000; in baboons: Vick, Bovet, \& Anderson, 2001). Furthermore, monkeys use humans' state of the eyes as a cue to adjust behaviour in competitive situations (e.g. Flombaum \& Santos, 2005; Vick \& Anderson, 2003). It is therefore puzzling that sensitivity to others' state of the eyes has hardly ever been evidenced in a communicative context, except in a few studies (Hattori et al., 2010; Hostetter et al., 2007;). Here, we found that baboons performed virtually no gestural behaviour when the human was absent, but produced most visual gestures when the human was facing them with her eyes open. This suggests that their requesting behaviour 
was not merely driven by the sight of the food. Instead, it appears to be genuine communication motivated by the presence of the human partner. Moreover, while the information provided by the head and body orientation may be sufficient for interpreting direction of attention in quadrupedal species (Emery, 2000), this study shows that baboons also use open eyes as a cue when it is available in a communicative context.

In one study very similar to ours, Kaminski et al. (2004) pointed out a hierarchical use of cues to attention by chimpanzees. The apes responded primarily to body orientation and secondarily to face orientation only when the experimenter's body was oriented towards them. The present study did not allow us to distinguish between the possibly hierarchical contribution of head and body cues. However, the baboons responded more with visual signals to the Eyes closed than the Back turned conditions, and neither body orientation by itself nor the state of the experimenter's eyes was a better predictor of the subjects' begging for food than the Eyes open condition which mixed both cues. This suggests that not only the state of the eyes but also body and head orientation were relevant cues to others' visual attention for olive baboons. However, it remains possible that baboons respond to the state of the eyes only when the human's body is oriented towards them.

If our findings seem contradictory to certain previous studies in which food was deposited on a platform (e.g. Kaminski et al., 2004; Povinelli \& Eddy, 1996), they do corroborate the findings from other studies in which food was held in the experimenter's hand (e.g. Hattori et al. 2010; Hostetter et al. 2007).This slight methodological difference may therefore deserve further discussion. As previously stressed for great apes, body orientation, but not face orientation, may convey information about the experimenter's physical ability to give food rather than information about her ability to perceive a visual signal (Kaminski et al., 2004; Tempelmann et al., 2011). We suggest that holding food in the hands may increase and keep constant the disposition of the human to give food regardless of body orientation. Under 
such circumstances, it is possible that subjects process more subtle cues to attention such as the open versus closed state of the experimenter's eyes when begging for food. In a similar experiment, capuchin monkeys, Cebus apella, successfully adjusted their requesting gestures to the attentional state of a human holding food in one hand, but failed to adjust their requesting gestures to the attentional state of a human when gestures had to be directed at food deposited on a table (Hattori et al., 2010). While both gestures are communicative, pointing towards food on a table appears to be a rather difficult task for monkeys (e.g. Hattori et al., 2010). More research is hence needed to understand whether pointing towards an external target and begging from an experimenter require differential cognitive means for attracting the partner's attention.

Wild baboons have been reported to use visual orienting behaviour to attract a partner's visual attention. For instance, they solicit help in conflicts by looking alternately to an opponent and a solicited helper (Packer, 1977). Here, we report evidence of gaze alternation supporting gestural communication that was tuned to the visual attention of the recipient. Gaze alternation has long been considered as a corners tone of the developme nt of intentional communication in human infants (Bates et al., 1975; Camaioni et al., 2004; Franco \& Butterworth, 1996). In line with a previous study (Meunier et al., 2012), our baboons displayed visual orienting behaviour that was related not only to the locations of the social partner and the object of interest, but also to the state of the eyes of the experimenter. This suggests that baboons understand others' visual attention as a prerequisite for coordinating their own attention with that of others towards an external target. This is reminiscent of children developing joint visual attention (Butterworth, 2004).

However, the fact that the state of the eyes is not always used as a cue by nonhuman primates to infer attention direction (e.g. Kaminski et al., 2004; Maille et al., 2012; Povinelli \& Eddy, 1996), or when it is used it does not necessarily supplant head and body cues (e.g. 
this study), has led some to contrast simple learning of cues to attention with actual understanding of visual attention (Gómez, 1998; Povinelli \& Eddy, 1996). In this respect, it is likely that, owing to explicit training, baboons discriminated cues to the Eyes open condition as cues that increased the likelihood of getting the reward. However, neither visual orientating nor attention- getting behaviour was explicitly trained in the present study, yet it was flexibly adjusted to the visual attention of the experimenter. Baboons produced more visual gestures and visual orienting behaviours, but fewer attention-getting gestures when the experimenter could see them than when she could not. Whether baboons had implicitly learned these cues to attention during training or through prior experience, which may result in implicit knowledge of others' visual attention, is not possible to disentangle here. Whatever the operating process, it most probably led to an increased understanding of the conditions under which their communicative signals can be effective.

The use of acoustic communication (i.e. including vocalizations, nonvoiced sounds or bimodal communication such as visual/auditory-based gestures) as a means of attracting the attention of an otherwise inattentive partner has been reported in chimpanzees (Hopkins, Taglialatela, \& Leavens, 2007; Hostetter et al. 2007; Leavens et al. 2004), although not found in all studies (Tempelmann et al., 2011; Theall \& Povinelli, 1999). To our knowledge, our results are the first report of monkeys producing gestures as a means of elaborating communication that failed to elicit the desired outcome. We thus propose that baboons possess flexible communicative means that they can use with the same intent, although the present study did not systematically manipulate the expected outcome of the communicative exchange (but see Leavens et al, 2005). In contrast to a previous study that found baboons banged the cage as a result of frustration (Meunier et al., 2012), the behavioural pattern observed here does not result from thwarted communicative bids only, as evidenced by differential responses as a function of condition (owing to the fact that all experimental trials 
lasted for only $30 \mathrm{~s}$ and were systematically rewarded). Baboons produced more auditorybased gestures but fewer visual gestures when the experimenter could not see them, suggesting they might have used auditory communication as a substitute for visual communication to capture the attention of the experimenter.

This study brings critical insight to the interplay between intentional communication and social understanding through the primate lineage. Human infants (Liszkowski, Albrecht, Carpenter, \& Tomasello, 2008) and chimpanzees (Hopkins et al., 2007; Hostetter et al., 2007; Leavens et al., 2004) are known to use vocalizations as a means of recruiting their partner's attention. Here, we emphasize that Old World monkeys are also capable of shifting to acoustic communication when the recipient is not visually attending. In contrast to human infants and chimpanzees, this acoustic communication is purely gestural, not vocal. This find ing questions the evolutionary emergence of vocal intentional communication in the primate lineage. Intentional acoustic communication might have been 'scaffolded' onto the special intent to attract others' attention (see Falk, 2004), initially through gestural communication in Old World monkeys and progressively through both gestural and vocal communication in great apes, before turning out predominantly vocal in early humans. Future research may address this topical question of whether acoustic intentional communication might have appeared in evolution concomitantly to the understanding of another's attention.

\section{Acknowledgme nts}

This research was supported by French National Research Agency (ANR) grants; references ANR-08-BLAN-0011_01 and ANR-12-PDOC-0014. We thank B. Rosay and C. Canteloup for coding the video materials, V. Dufour and B. Dauvier for helpful discussions, and several anonymous referees for their valuable comments on the manuscript. 


\section{Supplementary Material}

434

435

Supplementary material is available, in the online version of this article, at doi

436

437

\section{References}

438

439

Bates, E., Camaioni, L., \& Volterra, V. (1975). The acquisition of performatives prior to

440 speech. Merrill-Palmer Quarterly, 21, 205-226.

441

Brown, H., \& Prescott, R. 2006. Applied mixed models in medicine. Chichester: J. Wiley.

442

Burnham, K. P., \& Anderson, D. R. 2004. Multimodel inference understanding AIC and BIC

443 in model selection. Sociological Methods \& Research, 33, 261-304.

444

Butterworth, G. 2004. Joint visual attention in infancy. In G. Bremner \& A. Fogel, (Eds.),

445

Blackwell handbook of infant development (pp. 213-240). Oxford: Blackwell.

446

Call, J., \& Tomasello, M. 2007. The gestural communication of apes and monkeys. New

447 York: Taylor \& Francis/L. Erlbaum.

448 Camaioni, L., Perucchini, P., Bellagamba, F., \& Colonnesi, C. 2004. The role of declarative 449 pointing in developing a theory of mind. Infancy, 5, 291-308.

450 Cartmill, E. A., \& Byrne, R. W. 2007. Orangutans modify their gestural signaling according 451 to their audience's comprehension. Current Biology, 17, 1345-1348. 
452 Corballis, M. C. 2003. From mouth to hand: Gesture, speech, and the evolution of right-

453 handed ness. Behavioral and Brain Sciences, 26, 199-208.

454 Emery, N. J. 2000. The eyes have it: The neuroethology, function and evolution of social 455 gaze. Neuroscience \& Biobehavioral Reviews, 24, 581-604.

456 Estes, R. D. 1991. The behavior guide to African mammals: Including hoofed mammals,

457 carnivores, primates. Los Angeles: University of California Press.

458 Falk, D. 2004. Prelinguistic evolution in early hominins: Whence motherese? Behavioral and 459 Brain Sciences, 27, 491-503.

460 Flombaum, J. I., \& Santos, L. R. 2005. Rhesus monkeys attribute perceptions to others.

461 Current Biology, 15, 447-452.

462 Franco, F., \& Butterworth, G. 1996. Pointing and social awareness: declaring and requesting 463 in the second year. Journal of Child Language, 23, 307-336.

464 Genty, E., Breuer, T., Hobaiter, C., \& Byrne, R. W. 2009. Gestural communication of the gorilla (Gorilla gorilla): repertoire, intentionality and possible origins. Animal Cognition, 12, $527-546$.

467 Genty, E., \& Byrne, R. 2010. Why do gorillas make sequences of gestures? Animal 468 Cognition, 13, 287-301.

469 Gómez, J. C. 1998. Assessing theory of mind with nonverbal procedures: Problems with 470 training methods and an alternative procedure. Behavioral and Brain Sciences, 21, 119-120.

471 Gómez, J. C. 2005. Requesting gestures in captive monkeys and apes: Conditioned responses 472 or referential behaviours? Gesture, 5, 91-105. 
473 Gómez, J.-C. 2007. Pointing behaviors in apes and human infants: A balanced interpretation.

$474 \quad$ Child Development, 78, 729-734.

475 Hattori, Y., Kuroshima, H., \& Fujita, K. 2010. Tufted capuchin monkeys (Cebus apella) show 476 understanding of human attentional states when requesting food held by a human. Animal 477 Cognition, 13, 87-92.

478 Hobaiter, C., \& Byrne, R. 2011. The gestural repertoire of the wild chimpanzee. Animal 479 Cognition, 14, 745-767.

480

481

482

483

484

485

486

487

488

489

490

491

492

493

Hopkins, W. D., Taglialatela, J. P., \& Leavens, D. A. 2007. Chimpanzees differentially produce novel vocalizations to capture the attention of a human. Animal Behaviour, 73, 281286.

Hopkins, W. D., \& Vauclair, J. 2012. Evolution of behavioral and brain asymmetries in primates. In K. R. Gibson, \& M. Tallerman (Eds.), Handbook of language evolution (pp. 184197). Oxford: Oxford University Press.

Hostetter, A. B., Cantero, M., \& Hopkins, W. D. 2001. Differential use of vocal and gestural communication by chimpanzees (Pan troglodytes) in response to the attentional status of a human (Homo sapiens). Journal of Comparative Psychology, 115, 337-343.

Hostetter, A., Russell, J., Freeman, H., \& Hopkins, W. 2007. Now you see me, now you don't: evidence that chimpanzees understand the role of the eyes in attention. Animal Cognition, 10, 55-62.

Kaminski, J., Call, J., \& Tomasello, M. 2004. Body orientation and face orientation: two factors controlling apes' begging behavior from humans. Animal Cognition, 7, 216-223. 
494 Keating, C. F., \& Keating, E. G. 1982. Visual scan patterns of rhesus monkeys viewing faces.

$495 \quad$ Perception, 11, $211-219$.

496 Kummer, H. 1968. Social organization of hamadryas baboons: A field study. Chicago: The 497 University of Chicago Press.

498 Kyes, R. C., \& Candland, D. K. 1987. Baboon(Papio hamadryas) visual preferences for 499 regions of the face. Journal of Comparative Psychology, 101, 345-348.

500 Leavens, D. A. 2004. Manual deixis in apes and humans. Interaction Studies, 5, 387-408.

501 Leavens, D. A., \& Hopkins, W. D. 1999. The whole-hand point: The structure and function of 502 pointing from a comparative perspective. Journal of Comparative Psychology, 113, 417-425.

503 Leavens, D. A., Hostetter, A. B., Wesley, M. J., \& Hopkins, W. D. 2004. Tactical use of 504 unimodal and bimodal communication by chimpanzees, Pan troglodytes. Animal Behaviour, $505 \quad 67,467-476$. Leavens, D. A., Russell, J. L., \& Hopkins, W. D. 2005. Intentionality as measured in the persistence and elaboration of communication by chimpanzees (Pan troglodytes). Child Development, 76, 291-306.

Liebal, K., \& Call, J. 2012. The origins of non-human primates' manual gestures. Philosophical Transactions of the Royal Society B, 367, 118-128.

Liebal, K., Call, J., \& Tomasello, M. 2004. Chimpanzee gesture sequences. Primates, 64, 377-396. adjust to the attentional state of others. Interaction Studies, 5, 199-219. 
515

516

517

518

519

520

521

522

523

524

525

526

527

528

529

530

531

532

533

534

535

Liebal, K., Pika, S., \& Tomasello, M. 2006. Gestural communication of orangutans (Pongo pygmaeus). Gesture, 6, 1-38.

Liszkowski, U., Albrecht, K., Carpenter, M., \& Tomasello, M. 2008. Infants’ visual and auditory communication when a partner is or is not visually attending. Infant Behavior and Development, 31, 157-167.

Lorincz, E. N., Baker, C. I., \& Perrett, D. I. 2000. Visual cues for attention following in rhesus monkeys. In J. Fagot (Ed.), Picture perception in animals (pp. 343-372). New York: Psychology Press.

Maille, A., Engelhart, L., Bourjade, M., \& Blois-Heulin, C. 2012. To beg, or not to beg? That is the question: mangabeys modify their production of requesting gestures in response to human's attentional states. PLoS ONE, 7, e41197.

Martin-Malivel, J., Mangini, M. C., Fagot, J., \& Biederman, I. 2006. Do humans and baboons use the same information when categorizing human and baboon faces? Psychological Science, $17,599-607$.

Meguerditchian, A., Cochet, H., \& Vauclair, J. 2011. From gesture to language: Ontogenetic and phylogenetic perspectives on gestural communication and its cerebral lateralization. In A. Vilain, C. Abry, J.-L. Schwartz, \& J. Vauclair (Eds.), Primate communication and human language: Vocalisation, gestures, imitation and deixis in humans and non-humans (pp. 91120). Amsterdam: John Benjamins.

Meguerditchian, A., \& Vauclair, J. 2006. Baboons communicate with their right hand. Behavioural Brain Research, 171, 170-174. 
536

537

538

539

540

541

542

543

544

545

546

547

548

549

550

551

552

553

554

555

556

557

Meunier, H., Prieur, J., \& Vauclair, J. 2012. Olive baboons communicate intentionally by pointing. Animal Cognition, 16, 155-163.

Packer, C. 1977. Reciprocal altruism in Papio anubis. Nature, 265, 441-443.

Perlman, M., Tanner, J. E., \& King, B. J. 2012. A mother gorilla's variable use of touch to guide her infant: Insights into iconicity and the relationship between gesture and action. In S.

Pika, \& K. Liebal (Eds.), Developments in primate gesture research.. (Vol XIII, pp. 55-71). Amsterdam: John Benjamins.

Pika, S. 2008. Gestures of apes and pre-linguistic human children: Similar or different? First Language, 28, 116-140.

Pika, S., \& Liebal, K. 2012. Developments in primate gesture research. Amsterdam: John Benjamins.

Pika, S., Liebal, K., Call, J., \& Tomasello, M. 2005. Gestural communication of apes. Gesture, 5, 41-56.

Pollick, A. S., \& de Waal, F. B. M. de. 2007. Ape gestures and language evolution. Proceedings of the National Academy of Sciences, U.S.A., 104, 8184-8189.

Povinelli, D. J., \& Eddy, T. J. 1996. Factors influencing young chimpanzees' (Pan troglodytes) recognition of attention. Journal of Comparative Psychology, 110, 336-345.

Povinelli, D. J., Eddy, T. J., Hobson, R. P., \& Tomasello, M. 1996. What young chimpanzees know about seeing. Monographs of the Society for Research in Child Development, 61, i-189.

Reddy, V. 2004. Mind knowledge in the first year: Understanding attention and intention. In Bremner \& A. Fogel (Eds.), Blackwell handbook of infant development (pp. 241-264). Oxford: Blackwell. 
558

559

560

561

562

563

564

565

566

567

568

569

570

571

572

573

574

575

576

577

Scaife, M., \& Bruner, S. J. 1975. The capacity for joint visual attention in the infant. Nature, 253, 265-266.

Scott, N. M., \& Pika, S. 2012. A call for conformity: Gesture studies in human and nonhuman primates. In S. Pika, \& K. Liebal (Eds.), Developments in primate gesture research (Vol. XIII, pp. 147-164). Amsterdam: John Benjamins.

Tempelmann, S., Kaminski, J., \& Liebal, K. 2011. Focus on the essential: all great apes know when others are being attentive. Animal Cognition, 14, 433-439.

Theall, L. A., \& Povinelli, D. J. 1999. Do chimpanzees tailor their gestural signals to fit the attentional states of others? Animal Cognition, 2, 207-214.

Tomasello, M., Call, J., \& Hare, B. 1998. Five primate species follow the visual gaze of conspecifics. Animal Behaviour, 55, 1063-1069.

Tomasello, M., Carpenter, M., Call, J., Behne, T., \& Moll, H. 2005. Understanding and sharing intentions: The origins of cultural cognition. Behavioral and Brain Sciences, 28, 675691.

Vauclair, J. 2004. Lateralization of communicative signals in nonhuman primates and the hypothesis of the gestural origin of language. Interaction Studies, 5, 365-386.

Vick, S.-J., \& Anderson, J. R. 2003. Use of human visual attention cues by olive baboons (Papio anubis) in a competitive task. Journal of Comparative Psychology, 117, 209-216.

Vick, S.-J., Bovet, D., \& Anderson, J. R. 2001. Gaze discrimination learning in olive baboons (Papio anubis). Animal Cognition, 4, 1-10. 
578 Whiten, A., \& Byrne, R. W. 1988. Tactical deception in primates. Behavioral and Brain

579 Sciences, 11, 233-244.

580 


\section{Training of the subjects}

583

584

585

586

587

588

589

590

591

592

593

594

595

596

597

598

599

600

601

602

603

604

All subjects took part in training trials. The procedure comprised three steps in which the experimenter stood in front of the cage of the focal subject holding a raisin in her open palm in front of the subject, while progressively increasing the distance to the cage. In the first step, the raisin was kept within the reach of the subject who extended one arm to grasp it in the experimenter's hand. In the second step, the distance increased up to the limit of being out of reach and the experimenter anticipated the attempt of the subject to reach the food in giving the subject the raisin each time the subject initiated an arm extension out of the cage. In the third step, the experimenter stood out of the subject's arm reach and went on giving the subject the raisin immediately after each initiation of arm extension. For the arm extensions being considered as begging gestures, we set postural criteria ensuring that manual actions were no longer mechanically effective: (1) the subject had not to try to grasp the raisin by rotating its shoulder so as to go further through the wire mesh; (2) the subject's fingers had to be extended in line with the hand and the arm. Subjects had to reach the criterion of $80 \%$ of valid gestures across three consecutive 10-trials sessions administered once a day.

\section{Replication with novel experimenters}

Two extra test sessions were performed with novel experimenters so as to exclude possible conditioned responses driven by the sight of the main experimenter. Baboons were presented once to a novel woman and once to a novel man in a 2 by 2 design relying on the experimenter's novelty (main experimenter versus novel experimenters first) and experimenter's sex (novel woman versus novel man first). Experimental procedure and data analysis were similar to those for the main experiment. 
Baboons showed similar behavioural trends when they were tested with novel

606

607

608

609

610

611

612

613

614

615

616

617

experimenters over two test sessions (see Appendix Fig. A1). They adjusted their begging behaviour to the visual attentional state of the experimenter (Main Model: AIC $=156.4$; chisquare tests for the log-likelihood ratios: Main Model - Null Model: $P<0.001)$. Baboons produced significantly more gestures in the Eyes open than in the Back turned (Wald test: $z=$ -4.20, $P<0.001$ ) and Out (Wald test: $z=-6.47, P<0.001)$ conditions, but not in the Eyes closed condition (Wald test: $z=-1.14, P=0.253$ ).

Body orientation by itself (Front/Back Model: AIC $=155.7)$ may consequently be a better predictor of subjects' responses than experimental conditions mixing both cues, although the two models did not differ significantly (chi-square tests for the log-likelihood ratios: Main Model - Front/Back Model: $P=0.251)$. However, the state of the experimenter's eyes was not an accurate predictor of the subjects' responses (Can see/Cannot see Model: AIC = 164.5; chi-square tests for the log-likelihood ratios: Main Model - Can see/Cannot see Model: $P<0.010)$.

These findings support the proposal that baboons' gestural communication is driven not by the sight of the food reward alone nor by the sight of the main experimenter who could have been associated with the delivery of the reward. We propose that baboons' begging gestures should be interpreted as genuine communicative attempts motivated by the presence of a partner whose cooperation is required to get the reward. Further testing is, however, needed to find out whether baboons processed well-known and novel faces differently and whether such differential treatment may explain why they did not rely on the state of the novel experimenter's eyes to adjust their communicative behaviour in this experiment. 
Dependent variable: number of begging gestures

$\begin{array}{llllll}\text { Null Model } & \text { None } & \text { Individual } & 812.10 & 510.11 & * * * \\ \text { Main Model } & \text { Condition } & \text { Individual } & \mathbf{3 0 1 . 9 9} & \mathbf{0 . 0 0} & / \\ \text { Time Model } & \text { Block, condition, block:condition } & \text { Individual:block } & 308.70 & 6.71 & \text { NS } \\ \text { Front/back Nested Model } & \text { Condition } & \text { Individual } & 305.19 & 3.20 & * \\ \text { Can see/cannot see Nested Model } & \text { Condition } & \text { Individual } & 356.19 & 54.20 & * * *\end{array}$

Dependent variable: number of gaze alternation bouts

Null Model

Main Model

\section{None}

Condition

$\begin{array}{llll}\text { Individual } & 281.70 & 45.21 & * * * \\ & & & \\ \text { Individual } & \mathbf{2 3 6 . 4 9} & \mathbf{0 . 0 0} & \text { / }\end{array}$




\section{Dependent va riable: number of attention-getting gestures}

638 


\begin{tabular}{|c|c|c|c|c|}
\hline Name & Sex & Age & Rearing history & Place of birth \\
\hline Anelka & Male & 6 & Mother reared & Captivity \\
\hline Katy & Female & 16 & Mother reared & Captivity \\
\hline Marius & Male & 14 & Mother reared & Captivity \\
\hline Momo & Male & 14 & Mother reared & Captivity \\
\hline Oscar & Male & 13 & Mother reared & Captivity \\
\hline Perfide & Female & 12 & Mother reared & Captivity \\
\hline Prise & Female & 12 & Mother reared & Captivity \\
\hline Raimu & Male & 11 & Mother reared & Captivity \\
\hline Rambo & Male & 11 & Nursery & Captivity \\
\hline Rodolphe & Male & 11 & Mother reared & Captivity \\
\hline Sabine & Female & 10 & Mother reared & Captivity \\
\hline Sestarde & Female & 10 & Mother reared & Captivity \\
\hline Toti & Male & 9 & Mother reared & Captivity \\
\hline Tulie & Female & 9 & Mother reared & Captivity \\
\hline Ubu & Male & 8 & Mother reared & Captivity \\
\hline Uranus & Male & 8 & Mother reared & Captivity \\
\hline
\end{tabular}


Table A2. Orders of exposure to experimental conditions

648

\begin{tabular}{llll}
\hline Subjects' & First session & Second session & Third session \\
group & & & \\
\hline
\end{tabular}

Group 1 Randomorder Randomorder Randomorder Random order

$\begin{array}{llll}1 & 2 & 3 & 4\end{array}$

Group 2 Randomorder Randomorder Randomorder Randomorder

$2 \quad 3 \quad 4 \quad 1$

Group 3 Random order Random order Random order Random order

$3 \quad 4 \quad 1 \quad 2$

Group 4 Randomorder Randomorder Randomorder Randomorder

$\begin{array}{llll}4 & 1 & 2 & 3\end{array}$

649

650 Random order 1: Eyes Open, Out, Eyes Closed, Back Turned; random order 2: Eyes Closed, 651 Eyes Open, Out, Back Turned; random order 3: Eyes Closed, Out, Back Turned, Eyes Open; 652 random order 4: Back Turned, Eyes Closed, Eyes Open, Out.

653

654 
658 Figure 1. Begging gestures: (a) unimanual with the right hand and (b) bimanual.
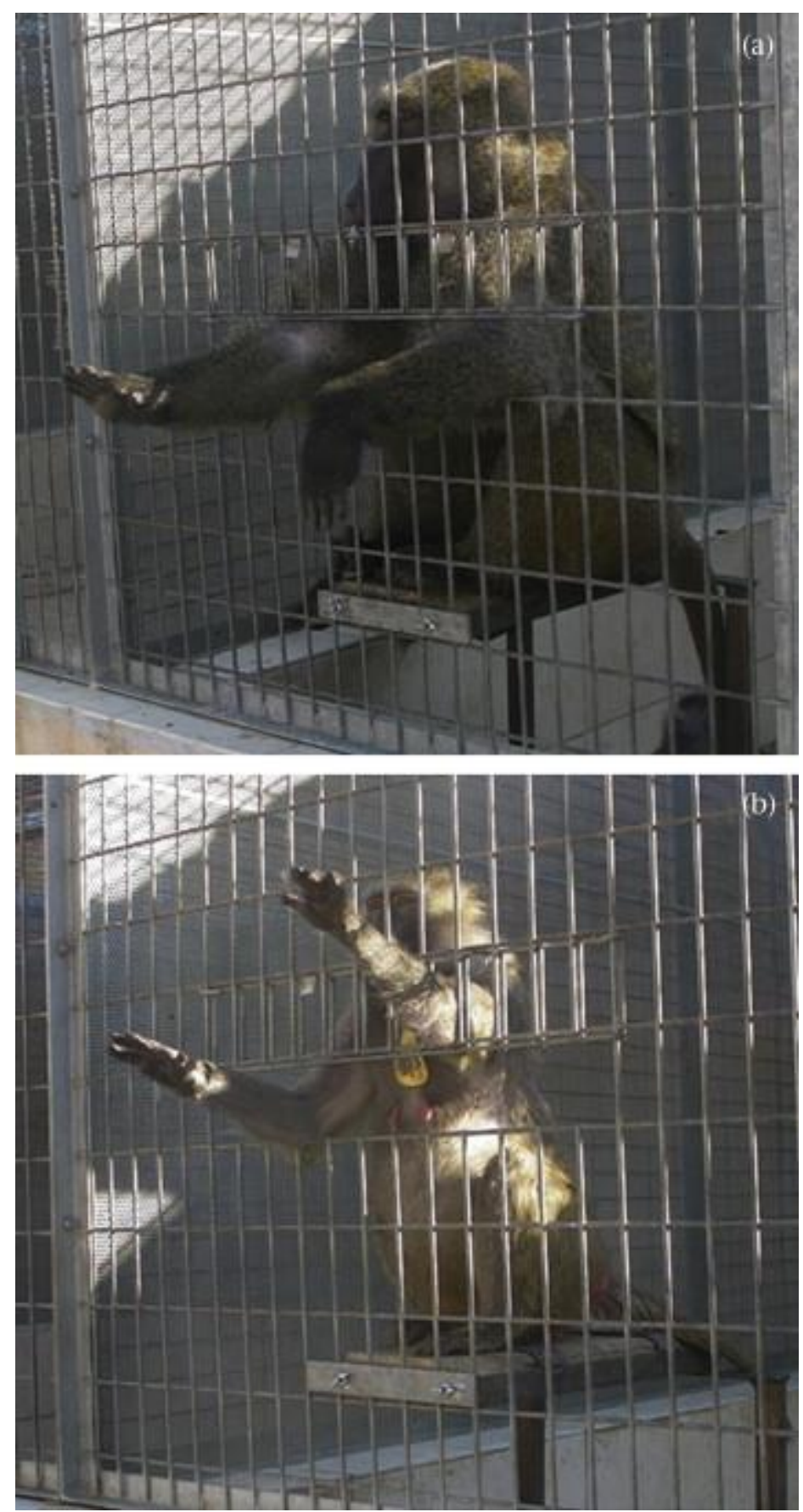
661 Figure 2. Mean rate/min $\pm \mathrm{SEM}$ of begging gestures for each experimental condition $(N=16$ 662 subjects).

663

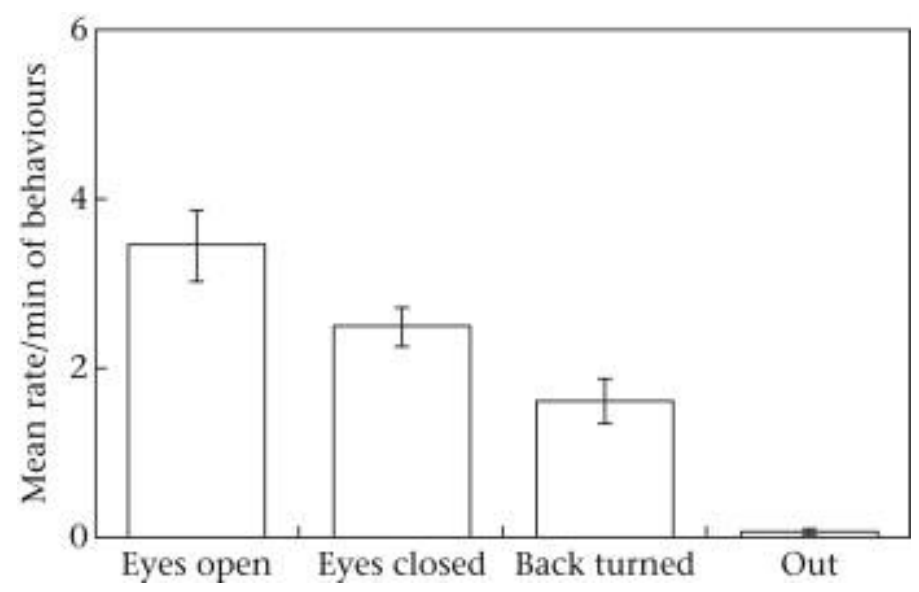

664 Figure 3. Mean rate/min \pm SEM of gaze alternation bouts for each experimental condition $(N$ $665=16$ subjects).

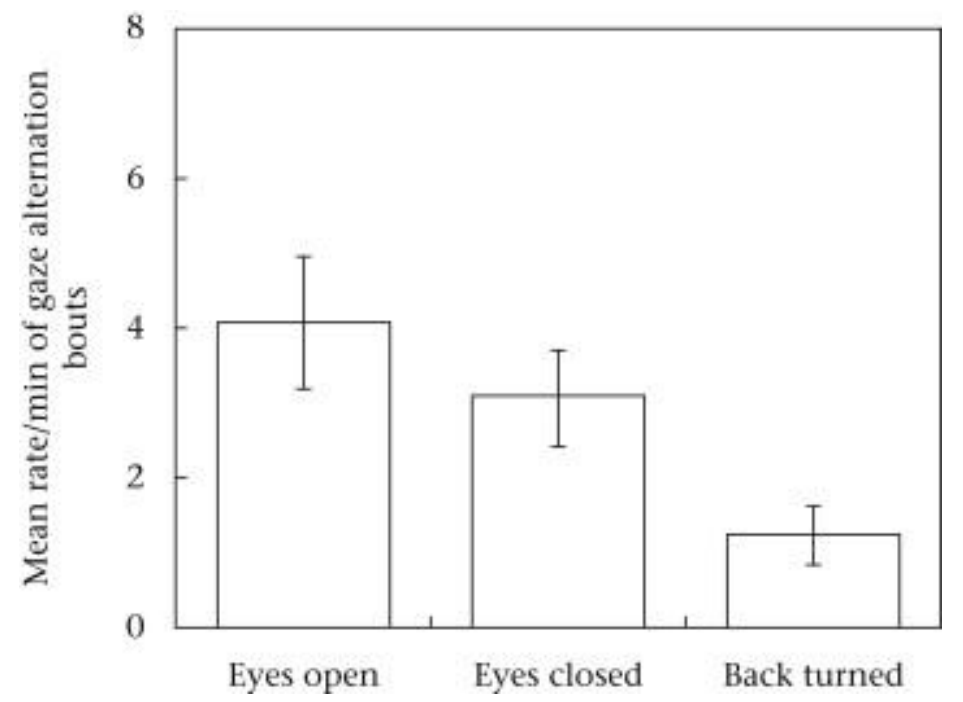

667 Figure 4. Mean rate/min \pm SEM of attention-getting gestures depending on experimenter's

668 visual attention during session block $1(N=16$ subjects $)$. One-sample permutation test: $* P<$ 669 0.05 . 


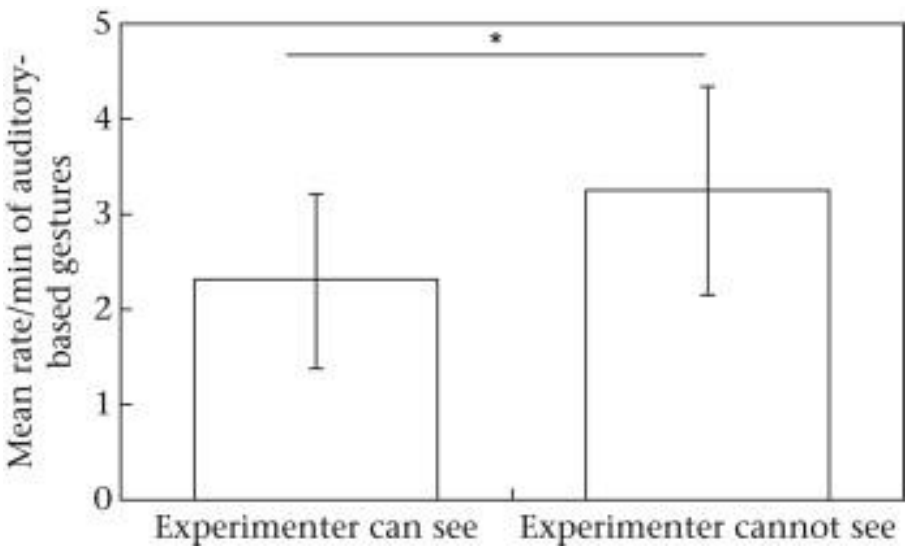

671 Figure 5. Percentages of visual and auditory-based gestures depending on experimenter's

672 visual attention during session block $1(N=16$ subjects $)$. Fisher's exact probability test: ***P

$<0.001$

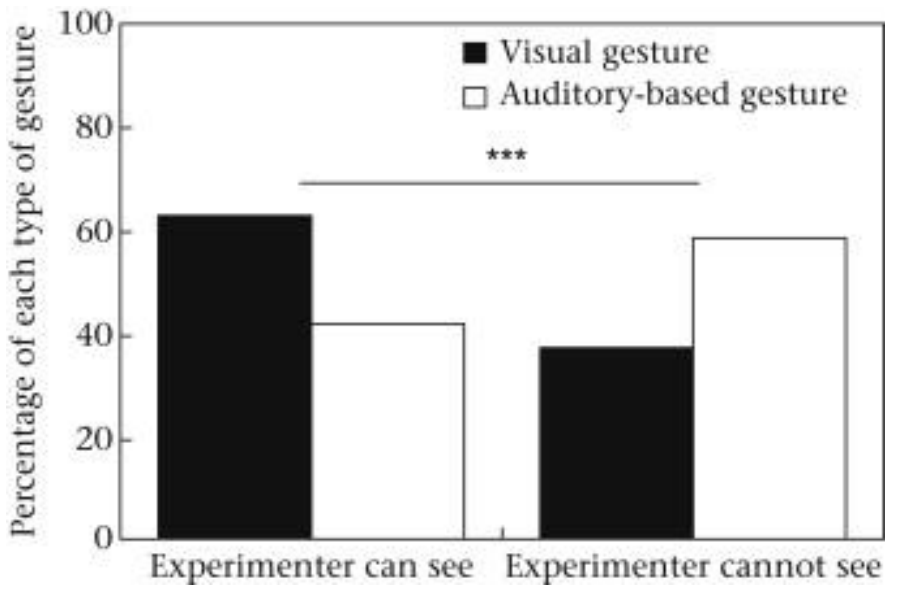

675 Figure A1. Mean rate/min \pm SEM of begging gestures towards novel experimenters for each experimental condition ( $N=15$ subjects).

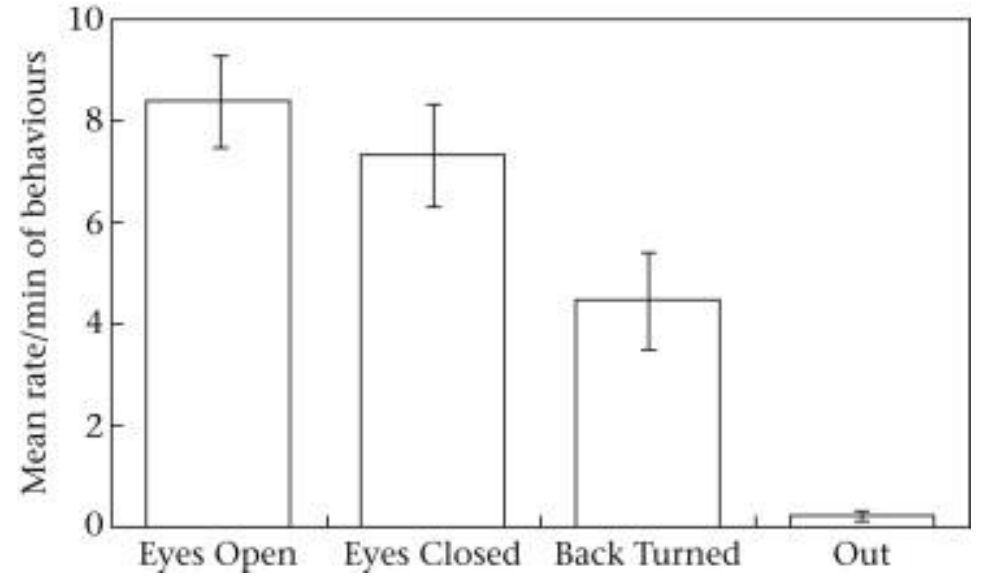

